\title{
Social Impulsivity Inversely Associated with CSF 5-HIAA and Fluoxetine Exposure in Vervet Monkeys
}

\author{
Lynn A. Fairbanks, Ph.D., William P. Melega, Ph.D., Matthew J. Jorgensen, Ph.D., \\ Jay R. Kaplan, Ph.D., and Michael T. McGuire, M.D.
}

\begin{abstract}
Animal and human research suggests that the central serotonin system is involved in the inhibition of impulsive behavior. Two studies were designed to assess this relationship in male vervet monkeys (Cercopithecus aethiops sabaeus) using a standardized test of impulsivity in a social context: the Intruder Challenge. In the first study, an index of impulsivity in response to an unfamiliar adult male intruder (including latency to approach and aggressive and assertive interactions) was inversely correlated with levels of the serotonin metabolite, 5-hydroxyindoleacetic acid (5-HIAA) in cisternal cerebrospinal fluid $(r=-0.33, \mathrm{p}<.01, \mathrm{n}=138)$. The
\end{abstract}

approach, but not aggressive, component of the Impulsivity Index was the primary contributor to this relationship (partial $r=-0.27, \mathrm{p}<.01$ ). The second experiment compared responses to the Intruder Challenge after 9 weeks of daily treatment with fluoxetine $(2 \mathrm{mg} / \mathrm{kg}, \mathrm{i} . \mathrm{m}$.) or vehicle. Fluoxetine-treated subjects $(\mathrm{n}=6)$ had significantly lower Impulsivity Index scores than controls $(\mathrm{n}=12)$. The results from these two investigations provide evidence for serotonergic influences on social impulsivity.

[Neuropsychopharmacology 24:370-378, 2001] (C) 2001 American College of Neuropsychopharmocology. Published by Elsevier Science Inc.
KEY WORDS: Impulsivity; Aggression; Serotonin; 5-hydroxyindoleacetic acid (5-HIAA); Fluoxetine; Primate

Impulsivity has been proposed as the common denominator in a variety of psychological disorders and sociological conditions that have been associated with indices of low central serotonergic functioning (Linnoila et

From the Department of Psychiatry and Biobehavioral Sciences (LAF, WPM, MJJ, MTM) and the Department of Molecular and Medical Pharmacology, University of California, Los Angeles, CA (WMP); Department of Pathology (Comparative Medicine), Wake Forest University School of Medicine, Wake Forest, IL (JRK); and Department of Psychiatry, Sepulveda Veterans Administration Medical Center, Sepulveda, CA (MTM).

Address correspondence to: Lynn A. Fairbanks, Neuropsychiatric Institute-UCLA, 760 Westwood Plaza, Los Angeles, CA 90024. Tel.: (310) 825-0782; E-mail: LFairbanks@mednet.ucla.edu

Received November 16, 1999; revised August 22, 2000; accepted September 14, 2000. al. 1993). For example, low levels of the serotonin metabolite, 5-hydroyxindoleacetic acid (5-HIAA) in cerebrospinal fluid (CSF) have been related to violent suicide attempts, impulsive fire-setting, violent and unprovoked aggression, and early onset alcoholism (Brown et al. 1982; Mann 1999; Virkkunen et al. 1994). Impulsivity and impulsive aggression have also been associated with blunted response to pharmacological challenges with serotonin agonists in personality-disordered and substance abusing men (Coccaro et al. 1997; Moeller et al. 1994). Recently, Manuck et al. (1998) reported significant inverse correlations between prolactin response to fenfluramine and measures of impulsivity and aggressiveness in men from a community-based sample. This latter study suggests that psychosocial disorders involving impulsive aggression may represent the extremes of normal dimensions of personality and underlying neurochemistry. 
A number of models have proposed that the monoaminergic neurotransmitters modulate the expression of basic personality dimensions (Cloninger 1987; Depue et al. 1994; Zuckerman 1996). These models generally agree that dopamine is associated with behavioral activation, and serotonin with behavioral inhibition. For example, Cloninger (1987) links the dopamine system with novelty seeking and serotonin with harm avoidance, while Zuckerman (1996) proposes that impulsive sensation seeking is a joint function of a highly reactive dopaminergic system and a weakly reactive serotonergic system.

Empirical research to test the above hypotheses uses a variety of methods to measure impulsivity. Human studies typically use self-report interviews or questionnaires, but the different inventories designed to measure this construct frequently do not correlate highly with one another (Barratt 1994; Eysenck et al. 1985; Parker and Bagby 1997). In contrast, for animal studies impulsivity has usually been inferred from responses in tasks that measure the ability to inhibit spontaneous or previously learned behavior (e.g., passive avoidance, approach-avoidance, or punished responses) (Soubrie 1986; Evenden 1999). When human subjects are tested with similar paradigms, however, the results do not correlate well with impulsivity measures from personality inventories (White et al. 1994). Several researchers have proposed that impulsivity is multifaceted, but there is presently no general agreement as to what its components are or how they should be measured (Evenden 1999; Parker and Bagby 1997).

Many of the problems associated with impulsivity and impulsivity disorders occur in a social context. Yet standardized measurement techniques to assess impulsivity in humans or in rodent models rarely use social cues. Social and naturalistic measures, such as the quality of aggressive behavior, presence of bite wounds, early mortality and early emigration, have been used to infer impulsivity in research with nonhuman primates (Botchin et al. 1993; Higley et al. 1996a,c; Kaplan et al. 1995; Mehlman et al. 1994, 1995). Because these measures depend on spontaneous events, however, they require long periods of behavioral observation and/or free-ranging settings. We have recently developed a standardized challenge that employs a salient social stimulus (an unfamiliar intruder) to elicit individual differences in response tendencies. The Intruder Challenge produces a reliable and consistent index of social impulsivity, as validated in a large sample of adolescent and adult male vervet monkeys (Fairbanks 2001).

Here we present the results of two studies evaluating aspects of the central serotonin system in relation to social impulsivity in vervet monkeys using the Intruder Challenge paradigm. In the first, we test the hypothesis that variation in social impulsivity is related to individual differences in levels of the metabolites of serotonin
(5-HIAA), and dopamine (homovanillic acid [HVA]) measured in CSF. Based on the prior literature, we hypothesized that high social impulsivity would be related to low CSF 5-HIAA levels and a low 5-HIAA/ HVA ratio. The second study assessed the effects of a 9-week course of fluoxetine (a serotonin reuptake inhibitor) on social impulsivity. We hypothesized that the resulting alterations in extracellular serotonin, and/or neuroadaptations affected by chronic fluoxetine, would result in lower levels of social impulsivity in treated animals compared to controls.

\section{STUDY 1: RELATIONSHIP BETWEEN SOCIAL IMPULSIVITY AND 5-HIAA}

\section{Methods}

Subjects. The subjects were 138 male vervet monkeys (Cercopithecus aethiops sabaeus) living in social groups at the UCLA/VA Vervet Monkey Research Colony. All groups were housed in outdoor enclosures, with chain link sides and adjacent enclosed night rooms. The American Association for the Accreditation of Laboratory Animal Care has approved the facility, and animal care is in accordance with the NIH Guide for the Care and Use of Laboratory Animals.

Subjects varied in age from 3.5 to 18 years, but most were adolescent or young adult (28 3-year-olds, 254 -yearolds, 31 5-year-olds, 31 6-8-year-olds, 23 9-year-olds or older). Eruption of the third molar occurs at age four for vervet males, and full adult size and completed dentition is achieved at age five. Most of the males were living in naturally composed mixed-sex social groups $(n=$ 106). The remaining $(n=32)$ lived in all-male groups. All animals were born and reared in the colony by their mothers. There were no changes in group composition or dominance rank within the groups between the time of behavioral assessment and CSF collection.

Intruder Challenge. In the Intruder Challenge test, 3 or 4 males were locked in the outdoor portion of the home enclosure and all other group members were confined to the indoor night room. Subjects were free to move around the outdoor area. At the beginning of the test session, an individual cage $\left(31^{\prime}\right.$ high $\times 24^{\prime}$ wide $\times$ $28^{\prime}$ deep) containing an unfamiliar adult male (the intruder) was placed at the edge of the enclosure, touching the outside of the chain link fence. The intruders were selected from animals unfamiliar to the subjects, and were not included in the study sample.

Using one observer per subject, the behavior of each animal was scored as present or absent in 1-min intervals over a 30-min test session. Behavior categories included behaviors directed toward the intruder (approach to within $1 \mathrm{~m}$; sit within $1 \mathrm{~m}$; touch, muzzle, 
threaten, and agonistic display), anxiety-related behaviors (pacing, scratching), aggression directed toward other group members or neighboring groups, and nondirected expressions of arousal (yawn, erection). Spatial position and head orientation were coded in point samples at the end of each minute. Latency to approach the intruder was recorded when the subject first moved to within $1 \mathrm{~m}$ of the intruder's cage. Inter-rater reliability for scores on individual behaviors from this data set ranged from $r=0.94$ (threaten) to $r=1.00$ (within $1 \mathrm{~m}$ ).

CSF Collection. Cerebrospinal fluid samples were collected 1 to 2 months following behavioral assessment. Prior results from our laboratory and others have demonstrated that levels of 5-HIAA and HVA tend be stable and trait-like within individuals over this time period (Higley et al. 1996a,b; Raleigh et al. 1992). At the time of sample collection, the animals were fasted overnight, run into squeeze cage tunnels inside the night rooms and anesthetized with $8-10 \mathrm{mg} / \mathrm{kg}$ ketamine hydrochloride administered intramuscularly. Approximately $0.5 \mathrm{ml}$ of CSF was withdrawn from the cisterna magna using a 22 gauge 1.5 inch short bevel hypodermic needle. The average time between administration of ketamine and sample collection was less than $10 \mathrm{~min}$.

After obtaining CSF samples, aliquots were centrifuged to remove any red blood cells, then transferred to amber polypropylene vials containing an equal volume of a solution containing $0.1 \mathrm{~N}$ perchloric acid, $0.1 \%$ sodium metabisulfite, and $0.05 \%$ EDTA. Samples were frozen at $-70^{\circ} \mathrm{C}$ until the time of the analysis.

HPLC Analysis of Serotonin and Dopamine Metabolites. An automated sample/injector unit was coupled to an HPLC system, consisting of a Shimazu solvent delivery system with a mobile phase of 9.5:90.5 (v/ v) of acetonitrile:aqueous buffer ( $75 \mathrm{mM} \mathrm{Na2HPO} 4,1.8$ $\mathrm{mM}$ octanesulfonic acid-sodium salt, $12 \mu \mathrm{M}$ EDTA, $\mathrm{pH}$ 3.1 ) at a flow rate of $0.8 \mathrm{ml} / \mathrm{min}$. An Alltech C18 reverse phase $(\mathrm{rp})$ column $(100 \times 4.6 \mathrm{~mm}, 3 \mu \mathrm{m}$ particle size $)$ preceded by a C18rp guard column $(7.5 \times 4.6 \mathrm{~mm}, 5$ $\mu \mathrm{m})$ was connected to an electrochemical detector (Coulochem II, ESA, Chelmsford, MA) set at an applied potential of $+0.02 \mathrm{~V}$ at detector 1 and $+0.40 \mathrm{~V}$ at detector 2 . Detector response was linear for $0.05-10 \mathrm{ng}(\mathrm{r}=0.99)$ for linear regression calculations of all compounds assayed; within-assay variance was less than $5 \%$ ). Peak areas for 5-HIAA and HVA were quantitated with the Rainin MACintegrator system.

Data Analysis. Because scores on individual behaviors were highly interrelated, principal components analysis was used to identify independent dimensions. The latency to approach and the frequency of the 6 active behaviors directed toward the intruder produced one strong factor (eigenvalue $=4.29$ ) with loadings greater than 0.50 for each of the variables. A positive score on this factor was associated with a short latency to approach the intruder and high scores for the number of intervals within $1 \mathrm{~m}$; sitting within $1 \mathrm{~m}$; and touching, sniffing, displaying to, and threatening the intruder. After reversing the latency score $(30$ - latency), these 7 measures were summed to produce a single score on a dimension from inhibited to impulsive, with a high score reflecting greater impulsivity. This index has been previously shown to be internally reliable (Cronbach's alpha $=0.84$ ) and consistent across trials (intraclass correlation coefficient $=0.83$ ) (Fairbanks 2001).

Pearson correlations and analysis of variance with polynomial contrasts were used to test the associations between the social impulsivity index and concentrations of 5-HIAA and HVA in CSF. Independent effects of one measure while controlling others were determined via partial correlation and stepwise linear regression. For the analysis of variance, impulsivity scores were divided into quartiles. Complete data on the behavioral and CSF measures were available for all 138 subjects in Study 1.

\section{Results}

The male monkeys varied considerably in their response to the unfamiliar intruder. Some of the males immediately rushed over to the intruder's cage, tried to reach in and touch the stranger, and threatened him at close range. Others avoided the intruder for the duration of the 30-min test period, or approached cautiously and threatened only from a safe distance. Males in the most impulsive quartile on the Impulsivity Index spent two-thirds of the time intervals within $1 \mathrm{~m}$ of the intruder, frequently reached into the intruder's cage, and threatened or displayed assertively to him in one-third of the intervals. In contrast, males in the most inhibited quartile took an average of $18 \mathrm{~min}$ to approach, spent less than 1 interval in front of the intruder, and never reached into the intruder's cage.

Table 1 shows the correlation matrix of the Social Impulsivity score, the two monoamine metabolites and age. Social Impulsivity was inversely correlated with 5-HIAA ( $\mathrm{r}=-.33, p<.001)$, as hypothesized. This result is depicted in Figure 1, which shows the mean ( \pm standard error) levels of 5-HIAA for each quartile on the Impulsivity scale. As suggested by the above correlation, there was a significant linear relationship between Impulsivity quartile and 5-HIAA ( $F=15.65$, $\mathrm{df}=1,134, p<.001)$. Simple contrasts between quartiles, with separate variance estimates, indicated that the mean level of 5-HIAA for Impulsive males was lower than that of the Moderately Inhibited $(p<.05)$ and Inhibited males $(p<.01)$.

Table 1 indicates that Social Impulsivity declined significantly with age. The mean and range of ages by Im- 
Table 1. Pearson Correlations Between Impulsivity Score and Metabolite Concentrations $(\mathrm{N}=138)$

\begin{tabular}{lccccc}
\hline & Impulsivity & 5-HIAA & HVA & 5-HIAA/HVA & Age \\
\hline Impulsivity & - & $-0.33^{* *}$ & $-0.18^{*}$ & $-0.23^{* *}$ & $-0.22^{* *}$ \\
5-HIAA & & - & $0.62^{* *}$ & $0.43^{* *}$ & 0.08 \\
HVA & & & - & $-0.41^{* *}$ & $-0.31^{* *}$ \\
5-HIAA/HVA & & & & - & $0.46^{* *}$ \\
\hline
\end{tabular}

${ }^{*} p<.05 ;{ }^{* *} p<.01$.

pulsivity quartile were as follows: most impulsive (mean $=5.2$ years, range $=3.5-14)$; moderately impulsive (mean $=6.2$ years, range $=3.5-13$ ); moderately inhibited (mean $=7.9$ years, range $=3.5-18$ ); most inhibited (mean $=6.2$ years, range $=3.5-13$ ). A partial correlation analysis of the independent contribution of 5-HIAA to Impulsivity, with age controlled indicated that when the effects of age were partialled out, the inverse correlation between 5-HIAA and Impulsivity was still statistically significant (partial $\mathrm{r}$ controlling age $=$ $-0.32, p<.001$ ). The correlation between Impulsivity and 5-HIAA was negative for every age group.

Levels of 5-HIAA were significantly correlated with HVA and the 5-HIAA/HVA ratio in this sample, and both of these measures were also inversely correlated with the Social Impulsivity index. A series of partial correlations and linear regressions were performed to determine the independent contribution of each of these variables to Impulsivity. The results indicated that when HVA was controlled, the inverse correlation between 5-HIAA and Impulsivity was still statistically significant (partial $\mathrm{r}$ controlling HVA $=-0.28, p<.01$ ). In contrast, after controlling for 5-HIAA, the correlation between HVA and Impulsivity was no longer signifi- cant (partial $r=0.03$, n.s.). The ratio of 5-HIAA to HVA did not contribute to the prediction of Impulsivity beyond the contribution of 5-HIAA alone (partial $\mathrm{r}=$ -0.10 , n.s.). These results suggest that the primary association in this data set is between the Impulsivity Index and 5-HIAA. Correlations of Impulsivity with HVA, or with the 5-HIAA/HVA ratio, can be explained by their relationship to 5-HIAA.

The Social Impulsivity scale consists of two components, an approach component and an aggressive component. The two subscales were positively correlated $(\mathrm{r}=0.61, p<.001)$, and each was negatively correlated with 5-HIAA (Approach: $\mathrm{r}=-0.31, p<.001$; Aggression: $(\mathrm{r}=-0.17, p<.05)$. When the independent association of each component with 5-HIAA was assessed, the inverse association of 5-HIAA with the Approach subscale was still statistically significant (partial $\mathrm{r}=$ $-0.27, p<.01$ ), but the relationship of 5-HIAA to the Aggression subscale was not (partial $r=0.04$, n.s.). Figure 2 shows the mean 5-HIAA levels for males that approached immediately versus those that waited more than a minute to approach, by high versus low aggressiveness. A 2-way analysis of variance of latency by aggression indicated that there was a significant effect of

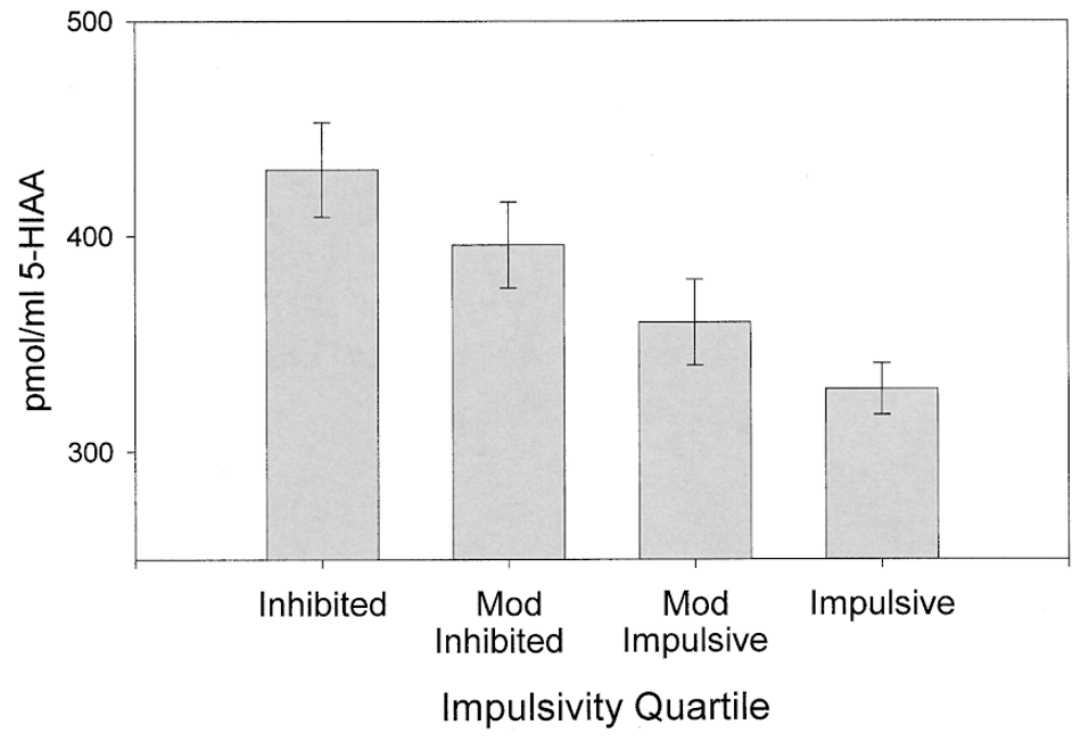

Figure 1. Mean $( \pm \mathrm{SE}) \mathrm{pmol} / \mathrm{ml}$ of 5 -HIAA, by quartile on the Impulsivity Index. (Impulsive, $n=34$; Moderately Impulsive, $n=34$; Moderately Inhibited, $n=37$; Inhibited, $n=33$ ). 


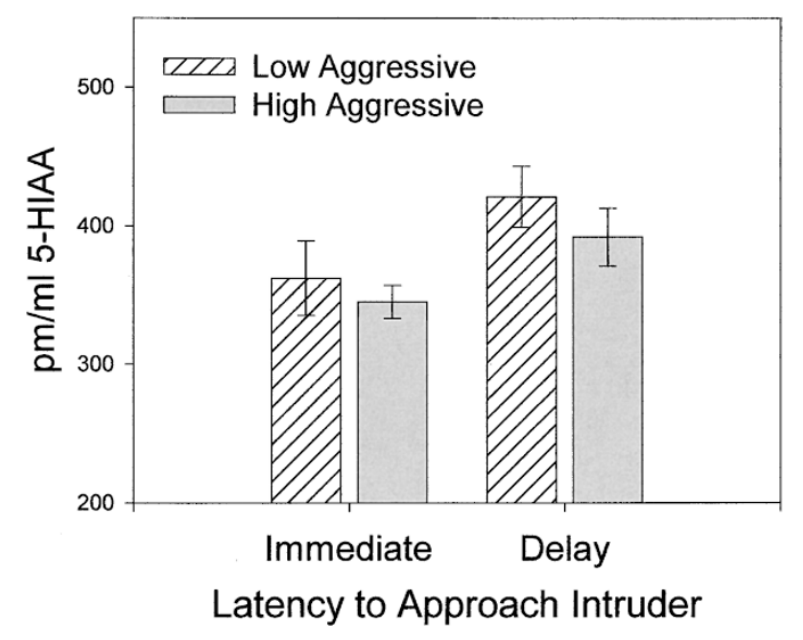

Figure 2. Mean $( \pm \mathrm{SE}) \mathrm{pmol} / \mathrm{ml}$ of 5 -HIAA, by latency to approach the intruder (Immediate: $<1 \mathrm{~min}$; Delay: $>1 \mathrm{~min}$ ) and by aggressiveness (above and below the median). (Immediate-low aggressive, $n=25$; Immediate-high aggressive, $n=46$; Delay-low aggressive, $n=38$; Delay-high aggressive, $n=29$ ).

latency $(\mathrm{F}=7.06, \mathrm{df}=1,134, p<.01)$, but the contribution of aggression was not statistically significant (1.24, $\mathrm{df}=1,134, p=.27)$. That is, irrespective of aggression, short latency animals had lower CSF 5-HIAA levels than did long latency animals.

An exploratory regression analysis was run to determine if 5-HIAA was associated with other behavioral dimensions in the Intruder Challenge test. Behaviors reflecting anxiety, arousal, and redirected aggression were included with the Impulsivity Index in a stepwise linear regression. The Impulsivity Index was the first variable to enter the equation, and no other measures added significantly to the prediction of 5-HIAA levels. The index of anxiety was not significantly related to 5-HIAA ( $\mathrm{r}=0.02$, n.s.) or HVA $(\mathrm{r}=-0.16$, n.s. $)$.

\section{STUDY 2: EFFECT OF FLUOXETINE ON SOCIAL IMPULSIVITY}

\section{Methods}

Subjects. The subjects were 18 adult male vervet monkeys living in 6 social groups at the UCLA/VA Vervet Monkey Research Colony. Each group initially contained 4 adult males, several adult females, and their offspring. Prior to treatment, the highest ranking adult male was removed from each of the 6 groups, leaving behind 3 lower ranking males as subjects for the present study. The age of the males varied from 6 to 16 years, with a mean of 9 years.

One male from each of the 6 social groups was randomly selected for treatment with fluoxetine and the remaining 2 males served as controls, resulting in a total of 6 treated and 12 control subjects. The treatment and control groups did not differ in age or pre-treatment dominance rank.

Treatment. Fluoxetine HCL (Sigma) was dissolved $(6 \mathrm{mg} / \mathrm{ml})$ in a solution that consisted of $6: 94(\mathrm{v} / \mathrm{v})$ of Tween 20:saline and then filter-sterilized $(0.22 \mu \mathrm{m})$. Vehicle injections were with the Tween 20:saline solution only. All injections were administered daily between 7-9 A.M. for 9 weeks. Treated males received $2 \mathrm{mg} / \mathrm{kg}$ i.m. fluoxetine, and control males received saline vehicle (Raleigh et al. 1985).

Intruder Challenge. The Intruder Challenge test, as described for Study 1, was conducted at the end of the treatment period. Observers were blind to subject's treatment status.

Data Analysis. The Impulsivity score was calculated as described above for Study 1. The nonparametric Mann-Whitney $U$ test was selected to compare group means in Study 2, because the variances were not homogeneous and the control group contained an outlying value.

\section{Results}

Mean Impulsivity scores for experimental and control animals are shown in Figure 3. Subjects treated with fluoxetine scored significantly lower in Impulsivity than control subjects (Mann-Whitney $\mathrm{U}=14, p<0.05$ ). Anxiety-related behaviors were also lower in the fluoxetine group, but the differences were not significant.

\section{GENERAL DISCUSSION}

In the studies reported here, social impulsivity in response to a stranger was related to individual differ-

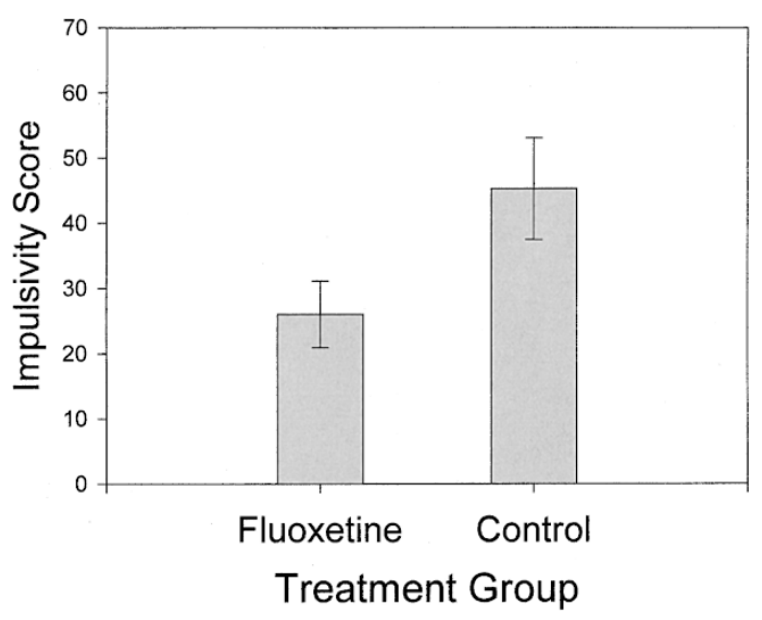

Figure 3. Mean $( \pm S E)$ score on the Impulsivity Index following 9 weeks of treatment with fluoxetine $(n=6)$ versus control solution $(n=12)$. 
ences in CSF 5-HIAA and was responsive to treatment with fluoxetine, a serotonin reuptake inhibitor. In Study 1 , males that immediately rushed over and challenged the intruder were lowest in CSF 5-HIAA, while those that avoided the intruder for the duration of the test period had the highest concentrations of CSF 5-HIAA. The results of Study 2 suggest, further, that this association may be causal, as animals treated with a serotonin reuptake inhibitor (fluoxetine) responded less impulsively to the intruder than did untreated controls. These results are consistent with the hypothesis that the central serotonin system contributes to the inhibition of impulsive behavior (Coscina 1997; Soubrie 1986).

There are several lines of evidence supporting the validity of the Social Impulsivity index from the Intruder Challenge test as a measure of a dimension of temperament from impulsive to inhibited. First, the behavioral reactions of males in the upper and lower quartiles provide face validity for the interpretation that animals scoring high in impulsivity are performing risk-laden behavior. Impulsive males (in the upper quartile of the index) immediately rushed over to an unfamiliar adult male without stopping to assess the consequences (Fairbanks 2001). They provoked the intruder with threats and assertive displays, and risked injury by positioning their faces and arms within reach of the intruder's hands and teeth. Males in the lowest quartile, in contrast, avoided contact with the intruder and only threatened from a safe distance. Second, the Impulsivity Index is sensitive to the increases in impulsivity in adolescence. Scores were highest for 4-year-old males, the age when vervet monkeys leave the safety of the natal group and challenge unfamiliar adult males for access to new groups (Fairbanks 2001). Third, the highest ranking adult males in each group were significantly more likely to score in the moderate range on the Impulsivity Index than at either extreme (Fairbanks, 2001). This suggests that the most impulsive and most inhibited males are less socially successful than more moderate males. Finally, the Intruder Challenge also produces an index of anxiety-related behaviors. Scores on the Anxiety Index were not significantly correlated with scores on the Impulsivity Index in this sample $(\mathrm{r}=$ -.12). This indicates that the Impulsivity Index is not simply reflecting individual differences in anxiety, but that impulsivity and anxiety are independent dimensions of temperament.

Impulsivity is often inferred as the common feature underlying aggressive behavioral disorders that have been associated with indices of low serotonin function (Coccaro et al. 1997; Linnoila et al. 1993). It is unclear, however, whether aggression is a necessary consequence of reduced serotonergic function, or whether it is but one of a family of behaviors that may be disinhibited depending on context, mood, and motivation. The present study provides data that allows partial disen- tanglement of the effects of serotonergic function on impulsivity versus effects on aggression. Although the test verified the presence of an inverse association between 5-HIAA and both impulsive and aggressive behavior in vervet males, further analysis demonstrated that impulsivity-inhibition was the principal dimension related to the serotonin metabolite. Aggression was correlated with 5-HIAA through its association with impulsive approach. This outcome could be interpreted as implying that the relationship between 5-HIAA and aggression was mediated through a general reduction in social inhibition. Our observations of the males' behavior indicated that the intruder was an evocative stimulus for all subjects. In males with low CSF 5-HIAA levels, response impulses were translated into immediate approach and confrontation. Males with high 5-HIAA levels also showed evidence of interest and arousal (through high rates of locomotion, scratching, yawning, vocalizing, and redirected aggression), but the urge to respond directly to the intruder was apparently inhibited.

Research concerning serotonin and impulsivity in humans and nonhuman primates is often discussed and interpreted in the context of neurochemical dysregulation and behavioral abnormality. The current study demonstrated that there is a linear relationship between 5-HIAA levels and response to an intruder throughout a broad range of behavioral expression, from relatively inhibited to impulsive. Thus, while some animals (those in the upper quartile for impulsivity with the lowest mean CSF 5-HIAA values) may have inappropriately put themselves at high risk through a disinhibited pattern of approach to a potentially dangerous stranger, there was an equal number of animals at the other extreme. Males in the most inhibited quartile were characterized by the highest CSF 5-HIAA levels. The inhibited males adopted a safe, conservative approach to the intruder, a reaction that may be less risky than that exhibited by the impulsive animals but that could lead to reduced success in male-male competition and loss of opportunities in challenging situations. In this data set, males that had attained the highest dominance rank in their social groups tended to be moderate in their responses to the intruder and were less likely than lower ranking males to be either extremely impulsive or extremely inhibited (Fairbanks 2001). Hence, variation in impulsivity-inhibition, and associated serotonin metabolism, could conceivably carry costs at the high as well as the low extreme. This latter conclusion is consistent with findings that elevated CSF 5-HIAA levels have been associated with overly inhibited and obsessive behavior in clinical populations. Positive correlations of CSF 5-HIAA with neuroticism and with obsessive-compulsive symptoms have been reported for patients with depression, anorexia and bulimia (Kaye et al. 1991, 1998; Roy 1999). 
Concentrations of monoamine metabolites in cisternal cerebrospinal fluid were used here as an indirect measure of neurotransmitter activity in the central nervous system (CNS). Although the relationship of 5 -HIAA to the overall functioning of the serotonin system has not been well defined (Commissiong 1985), there are several indications that monoamine metabolite levels are useful indicators of individual differences in underlying serotonergic processes. First, collection of CSF from the cisterna magna ensures that most of the metabolite obtained is derived from activity in the brain. Second, baseline concentrations of cisternal 5-HIAA and HVA have been shown to be consistent and traitlike within individuals (Higley et al. 1996a; Raleigh et al. 1992). Finally, the persistence of observations of correlations between 5-HIAA levels and behavioral measures of impulsivity and aggression across a wide range of human and non-human primate studies suggests that this index reflects relevant variation in some aspect of CNS neurotransmitter activity. A limitation of CSF measures is that they do not localize variation in activity to specific receptors. Such specificity is perhaps better obtained through targeted pharmacological challenge (Olivier and Mos 1992) or genetic manipulation. For example, studies with knockout mice suggest that serotonergic influences on impulsive and aggressive behavior may be mediated through $5-\mathrm{HT}_{1 \mathrm{~B}}$ receptors (Brunner and Hen 1997). Knockout mice lacking $5 \mathrm{HT}_{1 \mathrm{~B}}$ receptors are more aggressive than both wild type, and $5-\mathrm{HT}_{1 \mathrm{~A}}$ knockout mice in a resident intruder test (Saudou et al. 1994). The rapidity of attack in the isolationinduced aggression paradigm suggests, moreover, that $5-\mathrm{HT}_{1 \mathrm{~B}}$ receptors may modulate impulsivity as well as aggressiveness (Ramboz et al. 1996).

The results from Study 2 demonstrate that vervets treated with fluoxetine scored lower in social impulsivity than untreated controls. Although the mechanisms of action induced by chronic fluoxetine are not completely understood, several recent reports have found similar reductions in aggressiveness and related traits following treatment with serotonin reuptake inhibitors (SSRIs). For example, Coccaro and Kavoussi (1997) reported that fluoxetine significantly reduced scores on the Irritability and Aggression subscales of the Overt Aggression Scale of impulsive-aggressive personalitydisordered subjects. In a study of the effects of SSRI treatment on normal volunteers, Knutson et al. (1998) found that decreases in assaultiveness and irritability on the Buss-Durkee Hostility Inventory were related to plasma paroxetine levels following 4 weeks of treatment. Alcohol consumption, which has often been associated with impulsivity, has been shown to be reduced by SSRI treatment in human alcoholics (Tiihonen et al. 1996) and in a rhesus monkey model of excessive alcohol consumption (Higley et al. 1998). In contrast, paroxetine reduced harm avoidance and increased assertive- ness and boldness in patients with anxiety, depression or obsessive-compulsive disorder (Allgulander et al. 1998; Brody et al. 1999). These latter studies suggest that treatment with an SSRI may serve to normalize mood and behavior rather than move response tendencies consistently toward behavioral inhibition.

Human and animal research on serotonin-behavior relationships uses a variety of methods to measure impulsivity, aggression, and inhibition. The Intruder Challenge test employed in this research is a variant of resident-intruder paradigms designed to measure aggression in rats and mice (Olivier and Mos 1992). Here, the test was used to measure trait-like individual differences in social impulsivity. The Intruder Challenge produces a highly reliable and repeatable index of social impulsivity in a 30-min test session (Fairbanks 2001). The test can be used not only to measure extremes of impulsivity but also to quantify variation across the full range of individual differences from impulsive to inhibited. In the studies reported here, the Impulsivity Index was related to individual differences in CSF 5-HIAA, and was responsive to treatment with fluoxetine. The Intruder Challenge test, thus, provides a new method of measuring impulsivity that can extend our understanding of serotonergic influences on social behavior.

\section{ACKNOWLEDGMENTS}

The authors would like to thank Deborah Pollack, Karin Blau, Jill Cullen, Wendye Perrero, and Kelli Russell for assistance with data collection; Glenville Morton and Daniel Diekmann for help with animal handling; and Linda Schultz for her work on the CSF assays. This research was supported by a Veterans Administration Merit Review to Michael McGuire and funds from the Department of Psychiatry and Biobehavioral Sciences at UCLA.

\section{REFERENCES}

Allgulander C, Cloninger CR, Przybeck TR, Brandt L (1998): Changes on the Temperament and Character Inventory after paroxetine treatment in volunteers with generalized anxiety disorder. Psychopharmacol Bull 34:165166.

Barratt ES (1994): Impulsiveness and aggression. In Monahan J, Steadman HJ (eds), Violence and Mental Disorder. Chicago, University of Chicago Press, pp 61-79

Botchin MB, Kaplan JR, Manuck SB, Mann JJ (1993): Low versus high prolactin responders to fenfluramine challenge: Marker of behavioral differences in adult male cynomolgus macaques. Neuropsychopharmacology 9:93-99.

Brody AL, Saxena S, Silverman DHS, Alborzian S, Fairbanks LA, Phelps ME, Huang SC, Wu HM, Maidment K, Baxter LR (1999): Brain metabolic changes in major depressive disorder from pre- to post-treatment with paroxetine. Psych Res Neuroimag 91:127-139 
Brown GL, Ebert MH, Goyer PF, Jimerson DC, Klein WJ, Bunney WE, and Goodwin FK (1982): Aggression, suicide, and serotonin: relationships to CSF amine metabolites. Am J Psych 139:741-6

Brunner D, Hen R (1997): Insights into the neurobiology of impulsive behavior from serotonin knockout mice. Ann NY Acad Sci 836:81-105

Cloninger, CR (1987): A systematic method for clinical description and classification of personality. Arch Gen Psych 44:573-588

Coccaro EF, Kavoussi RJ, Trestman RL, Gabriel SM, Cooper TB, Siever LJ (1997): Serotonin function in human subjects: Intercorrelations among central 5-HT indices and aggressiveness. Psych Res 73:1-14

Coccaro EF, Kavoussi RF (1997): Fluoxetine and impulsive aggression in personality disordered subjects. Arch Gen Psych 54:1081-1088

Commissiong JW (1985): Monoamine metabolites: Their relationship and lack of relationship to monoaminergic neuronal activity. Biochem Pharmacol 34:1127-1131

Coscina DV (1997): The biopsychology of impulsivity: focus on brain serotonin. In Webster CD, Jackson MA (eds), Impulsivity: Theory, Assessment and Treatment. New York, Guilford Press, pp 95-115

Depue RA, Luciana M, Arbisi P, Collins P, Leon A (1994): Dopamine and the structure of personality: relation of agonist-induced dopamine activity to positive emotionality. J Person Soc Psych 67:485-498

Evenden JL (1999): Impulsivity: A discussion of clinical and experimental findings. J Psychopharmacol 13:180-192

Eysenck SBJ, Pearson PR, Easting G, Allsop JF (1985): Age norms for impulsiveness, venturesomeness and empathy in adults. Person Individ Dif 6:613-619

Fairbanks LA (2001): Individual differences in response to a stranger: Social impulsivity as a dimension of temperament in vervet monkeys. J Comp Psych 115.

Higley JD, King ST, Jr., Hasert MF, Champoux M, Suomi SJ, Linnoila M (1996a): Stability of interindividual differences in serotonin function and its relationship to severe aggression and competent social behavior in rhesus macaque females. Neuropsychopharmacology 14:67-76

Higley JD, Mehlman PT, Higley SB, Fernald B, Vickers J, Lindell SG, Taub DM, Suomi SJ, Linnoila M (1996b): Excessive mortality in young free-ranging male nonhuman primates with low cerebrospinal fluid 5-hydroxyindoleacetic acid concentrations. Arch Gen Psych 53:537-43

Higley JD, Mehlman PT, Poland RE, Taub DM, Vickers J, Suomi SJ, Linnoila M (1996c): CSF testosterone and 5-HIAA correlate with different types of aggressive behaviors. Biological Psychiatry 40,1067-82

Higley J, Hasert M, Suomi S, Linnoila M (1998): The serotonin reuptake inhibitor sertraline reduces excessive alcohol consumption in nonbuman primates: Effect of stress. Neuropsychopharmacology 18:431-443

Kaplan JR, Fontenot MB, Berard J, Manuck SB (1995): Delayed dispersal and elevated monoaminergic activity in free-ranging rhesus monkeys. Am J Primatol 35:229234
Kaye WH, Gwirtsman HE, George DT, Ebert MH (1991): Altered serotonin activity in anorexia nervosa after long-term weight restoration-Does elevated cerebrospinal fluid 5-hydroxyindoleacetic acid level correlate with rigid and obsessive behavior. Arch Gen Psych 48: 556-562

Kaye WH, Greeno CG, Moss H, Fernstrom J, Fernstrom M, Lilenfeld LR, Weltzin TE, Mann JJ (1998): Alterations in serotonin activity and psychiatric symptoms after recovery from bulimia nervosa. Arch Gen Psych 55:927935

Knutson B, Wolkowitz OM, Cole SW, Chan T, Moore EA, Johnson RC, Terpstra J, Turner RA, Reus VI (1998): Selective alteration of personality and social behavior by serotonergic intervention. Am J Psych 155:373-379

Linnoila M, Virkkunen M, George T, Higley D (1993): Impulse control disorders. International Scientific Symposium: Depression-OCD-anxiety (1993, Mainz, Germany). Int Clin Psychopharmacol 8:53-56

Mann JJ (1999): Role of the serotonergic system in the pathogenesis of major depression and suicidal behavior. Neuropsychopharmacology 21:S99-105

Manuck SB, Flory JD, McCaffrey JM, Matthews KA, Mann JJ, Muldoon MF (1998): Aggression, impulsivity and central nervous system serotonergic responsivity in a nonpatient sample. Neuropsychopharmacology 19:287-299

Mehlman PT, Higley JD, Faucher I, Lilly AA, Taub DM, Vickers J, Suomi SJ, Linnoila M (1994): Low CSF 5HIAA concentrations and severe aggression and impaired impulse control in nonhuman primates. Am J Psych 151:1485-1491

Mehlman PT, Higley JD, Faucher I, Lilly AA, Taub DM, Vickers J, Suomi SJ, Linnoila M (1995): Correlation of CSF 5-HIAA concentration with sociality and the timing of emigration in free-ranging primates. Am J Psych 152:907-913

Moeller FG, Steinberg JL, Petty F, Fulton M, Cherek DR, Dramer G, Garver DL (1994): Serotonin and impulsive/ aggressive behavior in cocaine dependent subjects. Prog Neuro-Psychopharmacol Biol Psychiat 18:10271035

Olivier B, Mos J (1992): Rodent models of aggressive behavior and serotonergic drugs. Prog Neuro-Psychopharmacol Biol Psych 16:847-870

Parker JDA, Bagby RM (1997): Impulsivity in adults: a critical review of measurement approaches. In Webster CD, Jackson MA (eds), Impulsivity: Theory, Assessment and Treatment. New York, Guilford Press, pp 142-157

Raleigh MJ, Brammer GL, McGuire MT, Yuwiler A (1985): Dominant social status facilitates the behavioral effects of serotonergic agonists. Brain Res 348:274-282

Raleigh MJ, Brammer GL, McGuire MT, Pollack DB (1992): Individual differences in basal cisternal cerebrospinal fluid 5-HIAA and HVA in monkeys: The effects of gender, age, physical characteristics, and matrilineal influences. Neuropsychopharmacology 7:295-304

Ramboz S, Saudou F, Amara DA, Belzung C, Segu L, Misslin R, Buhot MC, Hen R (1996): 5-HT1B receptor knockout - behavioral consequences. Behav Brain Res 73:305-312

Roy A (1999): CSF 5-HIAA correlates with neuroticism in depressed patients. J Affect Dis 52:247-249 
Saudou F, Amara DA, Dierich A, LeMeur M, Ramboz S, Segu L, Buhot MC, Hen R (1994): Enhanced aggressive behavior in mice lacking 5-HT1B receptor. Science 265:1875-1878

Soubrie, P (1986): Reconciling the role of central serotonin neurons in human and animal behavior. Behav Brain Sci 9:319-364

Tiihonen J, Ryynanen OP, Kauhanen J, Hakola HP, Salaspuro M (1996): Citalopram in the treatment of alcoholism: a double-blind placebo-controlled study. Pharmacopsych 29:27-29
Virkkunen M, Rawlings R, Tokola R, Poland RE (1994): CSF biochemistries, glucose metabolism, and diurnal activity rhythms in alcoholic, violent offenders, fire setters, and healthy volunteers. Arch Gen Psych 51:20-27

White JL, Moffitt TE, Caspi A, Bartusch DJ, Needles DJ, Stouthamer-Loeber M (1994): Measuring impulsivity and examining its relationship to delinquency. J Abnormal Psychol 103:192-205

Zuckerman, M (1996): The psychobiological model for impulsive unsocialized sensation seeking: A comparative approach. Neuropsychobiol 34:125-129 